Artículo original

\title{
Caracterización molecular de las variantes del virus de Epstein-Barr detectadas en la cavidad oral de adolescentes de Cali, Colombia
}

Daniela Arturo-Terranova ${ }^{1,2}$, Sebastián Giraldo-Ocampo ${ }^{2}$, Andrés Castillo $^{1}$

${ }^{1}$ Departamento de Biología, Facultad de Ciencias Naturales y Exactas, Universidad del Valle, Cali, Colombia

${ }^{2}$ Posgrado en Ciencias Biomédicas, Escuela de Ciencias Básicas, Facultad de Salud, Universidad del Valle, Cali, Colombia

Introducción. El virus de Epstein-Barr (EBV) es un virus ubicuo y oncogénico, asociado con el desarrollo de enfermedades como la mononucleosis infecciosa, el linfoma de Burkitt, el carcinoma nasofaríngeo y otras neoplasias. Actualmente, se reconocen dos subtipos: EBV-1 y EBV-2, que tienen diferencias genéticas con sus antígenos nucleares (Epstein-Barr Nuclear Antigens, EBNA). Debido a la gran heterogeneidad y variabilidad encontradas en la proteína LMP1 del virus, se han descrito variantes asociadas con ciertas enfermedades o con regiones geográficas específicas.

Objetivo. Identificar y caracterizar molecularmente las variantes del EBV detectadas en la cavidad oral de 84 adolescentes de Cali, Colombia.

Materiales y métodos. Se hizo la amplificación por reacción en cadena de la polimerasa (Polymerase Chain Reaction, PCR) convencional, así como la purificación y la secuenciación del gen $E B N A 3 C$ se realizó para subtipificar el virus y del dominio C-ter de la proteína LMP1 para identificar variantes. Además, se llevó a cabo un análisis filogenético y de variantes nucleotídicas de las secuencias obtenidas comparadas con variantes patogénicas y geográficas reportadas en el GenBank (National Center for Biotechnology Information, NCBI). Resultados. El subtipo viral predominante fue el EBV-1 (79 \%); el 72,6 \% se agrupó con la variante patogénica Raji, derivada de linfocitos $B$ de un paciente con linfoma de Burkitt; el $13,7 \%$ se relacionó con una variante de origen geográfico del Mediterráneo y otro 13,7\% no se agrupó con ninguna de las variantes de referencia.

Conclusiones. Este es el primer estudio que reporta variantes del gen LMP1-EBV en Cali, Colombia. Se requieren nuevos estudios para caracterizar la variante sin identificar y determinar si es patogénica o si es una variante geográfica presente exclusivamente en la ciudad.

Recibido: 30/01/2019

Aceptado: 20/01/2020

Publicado: $22 / 01 / 2020$

Citación:

Arturo-Terranova D, Giraldo-Ocampo S, Castillo A. Caracterización molecular de las variantes del virus de Epstein-Barr detectadas en la cavidad oral de adolescentes de Cali, Colombia. Biomédica. 2020;40(Supl.1):76-88.

https://doi.org/10.7705/biomedica.4917

Correspondencia:

Daniela Arturo, Carrera 1a D1 A No 56-135, Cali, Colombia

Teléfono: (310) 6032875

daniela.arturo@ correounivalle.edu.co

Contribución de los autores:

Daniela Arturo: análisis de laboratorio, consolidación y análisis de la información, escritura del artículo Sebastián Giraldo: análisis de laboratorio, consolidación de la información y revisión del artículo Andrés Castillo: diseño de la investigación y revisión del artículo

Financiación:

Vicerrectoría de Investigación de la Universidad del Valle, convocatoria interna 71114.

Conflicto de intereses:

Los autores no presentan ningún conflicto de intereses.
Palabras clave: infecciones por virus de Epstein-Barr; boca; filogenia; adolescente; Colombia.

Molecular characterization of Epstein-Barr virus variants detected in the oral cavity of adolescents in Cali, Colombia

Introduction: The Epstein-Barr virus (EBV) is an ubiquitous and oncogenic virus associated with the development of diseases such as infectious mononucleosis, Burkitt's lymphoma, nasopharyngeal carcinoma, and other neoplasms. Currently, two types are recognized: EBV-1 and EBV-2, which have genetic differences with their EBNA nuclear antigens. Likewise, due to the high degree of heterogeneity and variability found in the LMP1 protein of the virus, variants associated with pathogenesis or specific geographic regions have been described.

Objective: To identify and characterize molecularly EBV variants detected in the oral cavity of 84 adolescents in Cali, Colombia.

Materials and methods: Conventional PCR amplification, purification, and sequencing of the gen EBNA3C were carried out to typify the virus and the C-ter domain of the LMP1 protein to identify variants. We also conducted a phylogenetic and nucleotide variant analysis of the obtained sequences versus pathogenic or geographic variants reported in GenBank-NCBI.

Results: The predominant viral subtype was EBV-1 (79\%); $72.6 \%$ was grouped with the pathogenic variant Raji, derived from B lymphocytes of a patient with Burkittss lymphoma, $13.7 \%$ was related to a variant of Mediterranean origin, and $13.7 \%$ was not grouped with any of the reference variants.

Conclusions: This is the first time that variants of LMP1-EBV have been identified in Cali, Colombia. Additional studies are necessary to characterize the unidentified variant and to determine if it is pathogenic or if it is just an isolate present in the city of Cali.

Keywords: Epstein-Barr virus infections; mouth; phylogeny; adolescent; Colombia. 
El virus de Epstein-Barr fue descrito por primera vez en 1964 por Epstein, Achong y Barr (1). Pertenece a la familia Herpesviridae, a la subfamilia de Gammaherpesvirinae, y es el prototipo del género Lymphocryptovirus (2). El vehículo de trasmisión del EBV es principalmente la saliva (3), aunque se ha detectado ADN del virus en la leche materna y en algunas secreciones genitales, pero la información sobre esto último es todavía poca (4).

La partícula viral del EBV presenta una envoltura que contiene en su interior una nucleocápside conformada por un genoma de ADN de doble cadena de $172 \mathrm{kpb}$ rodeada de una cápside icosaédrica compuesta por 162 capsómeros (5). Se han descrito dos subtipos virales del EBV, el EBV de tipo 1 (EBV-1) y el de tipo 2 (EBV-2). Esta clasificación se basa en la presencia de polimorfismos en los genes que codifican los antígenos nucleares EBNA3A, EBNA3B y EBNA3C (6). Sin embargo, dado que estos polimorfismos no son suficientes para describir toda la variación natural del EBV, también se han descrito variantes con base en polimorfismos encontrados en otros antígenos virales, como la proteína latente de membrana 1 (LMP1) (7).

Clínicamente, el EBV se caracteriza por infectar persistentemente al $90 \%$ de la población mundial (8); además, es el agente etiológico de la mononucleosis infecciosa en niños (9) y adolescentes (10), y de la enfermedad linfoproliferativa posterio a trasplante (11). Según la International Agency for Research on Cancer, (IARC), se clasifica como un carcinógeno del grupo $1(12,13)$ asociado con tumores como el linfoma de Burkitt, el de Hodking y el no Hodking (14) y el carcinoma nasofaríngeo (15). Aún no está totalmente dilucidada la etiopatogenia del EBV para el desarrollo de neoplasias malignas; sin embargo, en algunos estudios se ha propuesto que ciertas proteínas virales, como la proteína LMP1, estarían implicadas en dichas condiciones (16).

La proteína LMP1, codificada por el gen BNLF1 viral, tiene un peso molecular de $66 \mathrm{kDa}$; cuando se expresa, se localiza en la membrana plasmática de las células infectadas y desempeña un papel importante en el desarrollo de las neoplasias (17). Está conformada por 386 aminoácidos sectorizados en tres dominios: un dominio N-terminal corto de los aminoácidos 1 a 23; seis segmentos hidrofóbicos transmembranales de los aminoácidos 24 a 186, y, por último, un dominio carboxilo terminal (C-ter) de los aminoácidos 187 a 386 (18). El dominio C-ter interactúa con proteínas celulares mediante regiones de activación denominadas CTAR1 y CTAR2, las cuales activan varias vías de señalización celular de la célula infectada (19).

Esta oncoproteína viral puede autorregularse por diferentes vías celulares (20) y posee la capacidad de transformar in vitro fibroblastos de roedores (21), y convertirlos en tumorogénicos in vivo (22). Además, puede actuar como el receptor celular CD40 constitutivamente activado, perteneciente a la familia de receptores del factor de necrosis tumoral (23), para estimular múltiples vías de señalización, de manera independiente del ligando, lo cual promueve el crecimiento, la proliferación celular, la supervivencia y la inhibición de la apoptosis (24).

Dado que las secuencias de los ácidos nucleicos del BNLF1 viral que codifican la región del dominio C-ter de la proteína LMP1 presentan una gran variabilidad entre los aislamientos con presencia del EBV, varios investigadores han propuesto los análisis filogenéticos de esta región para determinar subtipos o variantes moleculares según su origen geográfico y su asociación patológica $(25,26)$. 
Entre las variantes geográficas descritas, se han identificado las Med81, Med+ y Med- de la región del Mediterráneo; las China 1 y 2 de China; la NC de Carolina del Norte, y la Alaskan de Alaska. Entre las variantes identificadas en líneas celulares patogénicas, se cuentan: la Raji, la AG876 y la MUTU de pacientes africanos con linfoma de Burkitt (27-29); las cepas GD1, GD2, Cao y AKATA de pacientes con este linfoma o con carcinoma nasofaríngeo (30), y la B95.8 de un paciente con mononucleosis infecciosa (26).

En este sentido, las herramientas filogenéticas permiten describir espacial y temporalmente los virus con relación a su huésped, localizar el origen de una enfermedad en particular, determinar qué cepas y variantes poseen mayor posibilidad de propagación en el futuro, y determinar la vulnerabilidad de la población frente a un virus. El reconocimiento de las variantes y su posible asociación con regiones geográficas o diferentes enfermedades, podría contribuir al entendimiento de la enfermedad en la población.

En Colombia, los pocos estudios sobre el EBV se han centrado únicamente en determinar la seroprevalencia del virus y su relación con diversas enfermedades, por lo que hay muy poca información sobre sus variantes y su efecto en las personas. Por ello, el objetivo de este trabajo fue identificar y caracterizar molecularmente las variantes del virus de EpsteinBarr detectado en la cavidad oral de adolescentes de Cali.

\section{Materiales y métodos}

\section{Tipo de muestra}

Se analizaron 84 muestras de ADN positivas para EBV, procedentes de un estudio previo (31) aprobado por el Comité de Ética Humana de la Universidad del Valle (Acta $\mathrm{N}^{\circ}$ 008-017). En el estudio citado, se tomaron 374 muestras de enjuague bucal de la cavidad oral de jóvenes adolescentes de Cali. El ADN se extrajo con el estuche PrepMan Ultra Sample Preparation Reagent ${ }^{\mathrm{TM}}$ de Applied Biosystems y se almacenó a $-20^{\circ} \mathrm{C}$ en agua libre de nucleasas hasta el análisis para detectar el EBV. Para la detección del ADN viral, se usaron los cebadores EBV-F; 5'-CCT GGT CAT CCT TTG CCA-3' y EBV-R; 5'-TGC TTC GTT ATA GCC GTA GT-3' y la técnica de PCR convencional. La reacción amplificó un fragmento de 95 pb y se logró un porcentaje de detección del 26 \% (96/374).

\section{Determinación de subtipos del EBV}

Para determinar la presencia de subtipos del EBV, se amplificó el gen viral EBNA3C con la pareja de cebadores propuesta por Kingman, et al. (32), con los cuales el tamaño del amplicón producto de la PCR varía según el subtipo. Para el subtipo EBV-1, se obtiene un tamaño de 153 pb y, para el EBV-2, uno de 246 bp.

Los cebadores utilizados en la reacción de amplificación fueron: EBNA3Cfwd 5'- AGA AGG GGA GCG TGT GTT GT-3' y EBNA3Crev 5'-GGC TCG TTT TTG ACG TCG GC-3'.

Las siguientes fueron las condiciones de la PCR: una desnaturalización de cinco minutos a $95^{\circ} \mathrm{C}$; 35 ciclos de amplificación durante 30 segundos a $94^{\circ} \mathrm{C}, 30$ segundos a $60^{\circ} \mathrm{C}$ y un minuto a $72{ }^{\circ} \mathrm{C}$, y una extensión final de cinco minutos a $72{ }^{\circ} \mathrm{C}$. El volumen y concentración de los reactivos fue: $4 \mu \mathrm{l}$ de solución tampón de amplificación $5 \mathrm{X}$ (Tris-HCl $10 \mathrm{mM}$, pH 8,4, en solución tampón de $\mathrm{KCl} 50 \mathrm{mM}$ ), $0,8 \mu \mathrm{l}$ de $\mathrm{MgCl}_{2}$ a $50 \mathrm{mM}, 0,6 \mu \mathrm{l}$ de cada cebador a $10 \mu \mathrm{M} ; 1,2 \mu \mathrm{l}$ de dNTP a $5 \mathrm{mM}$ y $0,2 \mu \mathrm{l}$ de Taq polimerasa $5 \mathrm{U}$. La concentración final de los reactivos fue: solución tampón 1X, $\mathrm{MgCl}_{2} 2 \mathrm{mM}, 0,3$ 
$\mu \mathrm{M}$ y $1 \mathrm{U}$ cada cebador, respectivamente. Se completó hasta un volumen final de $20 \mu \mathrm{l}$ con 11,6 $\mu \mathrm{l}$ de agua libre de DNasas y $1 \mu \mathrm{l}$ de ADN.

Como controles positivos, se utilizaron muestras anteriormente determinadas por PCR para cada uno de los subtipos y una positiva para infección viral simultánea; como control negativo, se empleó la mezcla de PCR sin añadir ADN.

Los productos de la amplificación se separaron por electroforesis en geles de agarosa al 1,5\% teñidos con bromuro de etidio y se visualizaron en un transiluminador de luz ultravioleta.

\section{Amplificación y secuenciación del gen BNLF1 del EBV}

Para determinar la presencia de las variantes del EBV, se amplificó y secuenció un fragmento de $576 \mathrm{pb}$ del dominio carboxilo terminal del gen viral BNLF1 con la pareja de cebadores propuesta por Zuo, et al. (33), (33). Las variantes fueron analizadas filogenéticamente y caracterizadas molecularmente.

Los cebadores utilizados en la reacción fueron: BNLF1fwd 5'-GTG CGC CTA GGT TTT GAG AG-3' y BNLF1rev 5'-TTC CTT CTC TAA CGC ACT TTC TC -3'.

Las siguientes fueron las condiciones de la PCR: una desnaturalización de cinco minutos a $95^{\circ} \mathrm{C} ; 40$ ciclos de amplificación de 45 segundos a 94 ${ }^{\circ} \mathrm{C}$, de 45 segundos a $58^{\circ} \mathrm{C}$ y de un minuto a $72{ }^{\circ} \mathrm{C}$, y una extensión final de 10 minutos a $72^{\circ} \mathrm{C}$. El volumen y concentración de los reactivos fue: $4 \mu \mathrm{l}$ de solución tampón de amplificación $5 \mathrm{X}$ (Tris- $\mathrm{HCl} 10 \mathrm{mM}$, pH 8,4 en solución tampón de $\mathrm{KCl} 50 \mathrm{mM}$ ), 0,28 $\mu \mathrm{l}$ de $\mathrm{MgCl}_{2} 50 \mathrm{mM}, 0,8 \mu \mathrm{l}$ de cada cebador 10 $\mu \mathrm{M} ; 1,2 \mu \mathrm{l}$ de dNTPs $5 \mathrm{mM}$ y $0,2 \mu \mathrm{l}$ de Taq polimerasa $5 \mathrm{U}$. La concentración final de los reactivos fue: solución tampón $1 \mathrm{X}, \mathrm{MgCl}_{2} 0,7 \mathrm{mM}$, de cada cebador $0,4 \mu \mathrm{M}$, DNTPs $0,3 \mathrm{mM}$ y $1 \mathrm{U}$ de Taq. Se completó hasta un volumen final de $20 \mu \mathrm{l}$ con $11,72 \mu \mathrm{l}$ de agua libre de DNasas y $1 \mu \mathrm{l}$ de ADN.

Los productos de la amplificación se secuenciaron directamente mediante el método de Sanger de la empresa Macrogen, Inc., Corea.

\section{Análisis filogenético}

Para la construcción del árbol filogenético, se empleó el programa de análisis genético de evolución molecular MEGA, versión 7 (34), para analizar las secuencias obtenidas de nucleótidos de los fragmentos amplificados de la región carboxilo terminal del gen $B N L F 1$, las cuales se compararon con secuencias de referencia de las variantes del EBV almacenadas en la base de datos del GenBank-NCBI con los números de acceso: V01555.2 (B95.8); AY961628.3 (GD1); HQ020558.1 (GD2); KC207813.1 (Akata); X58140.1 (Cao); KF717093.1 (Raji); DQ279927.1 (AG876); AY337723.1 (China 1); AY337724.1 (China 2); AY337722.2 (Med +); AY337721.2 (Med-); AY337726.2 (NC); AY337725.1 (Alaskan); y KF373730.1 (M81).

En el análisis, todas las secuencias de nucleótidos se alinearon con el algoritmo Clustal W (35). Posteriormente, utilizando el criterio de inferencia bayesiana y con el paquete Models se seleccionó el modelo evolutivo que mejor se ajustaba a los resultados obtenidos en el alineamiento de las secuencias. Por último, se evaluó el árbol filogenético con el algoritmo de máxima verosimilitud y 100 réplicas de remuestreo. 


\section{Análisis de variantes}

Los cambios de aminoácidos del dominio carboxilo terminal de la proteína LMP1, a partir de las mutaciones no sinónimas del gen BNLF1, se determinaron con el programa Blastn, utilizando la opción 'CDS feature' y, como referencia de comparación, la secuencia del EBV (número de acceso en el GenBank-NCBI: NC_007605).

\section{Resultados}

\section{Determinación de los subtipos del EBV}

De las 96 muestras positivas para el EBV, en 84 se logró amplificar el tamaño de los fragmentos para determinar los subtipos, y se obtuvo el subtipo EBV-1 en el $79 \%$ (66/84) de estas muestras y, el subtipo EBV-2 en el $19 \%(16 / 84)$, en tanto que dos de las muestras presentaron ambos subtipos (figura 1 y cuadro 1 ).

\section{Determinación de las variantes de EBV}

En cuanto a la determinación de las variantes del EBV, en 29 de las 96 muestras se logró amplificar y secuenciar un fragmento de $576 \mathrm{pb}$ del gen $B N L F 1$, correspondiente a la región que codifica el dominio C-ter de la proteína LMP1 viral (figura 2).

\section{Análisis filogenético e identificación de variantes}

Las variantes de la proteína LMP1 se caracterizaron mediante la reconstrucción filogenética con secuencias prototipo del GenBank. El modelo de evolución para la elaboración de los tres análisis se determinó utilizando el programa MEGA 7, y se halló que el Jukes-Cantor (JC+G) era el más adecuado para el estudio; las tasas de sustitución encontradas para las secuencias fueron $[A C]=[C G]=0,166 ;[A G]=0,083 ;[A T]=0,083, y$ $[C T]=[G T]=0,166$, y las frecuencias de bases, $A=0,250 ; C=0,250 ; G=0,250$; $\mathrm{T}=0,250$, y $\mathrm{p}$-inv $=0,5$.

En la figura 3 se muestra la distribución de las secuencias de los EBV detectados en Cali, en relación con las variantes de referencia del virus ligadas a un área geográfica o a alguna de sus manifestaciones clínicas.

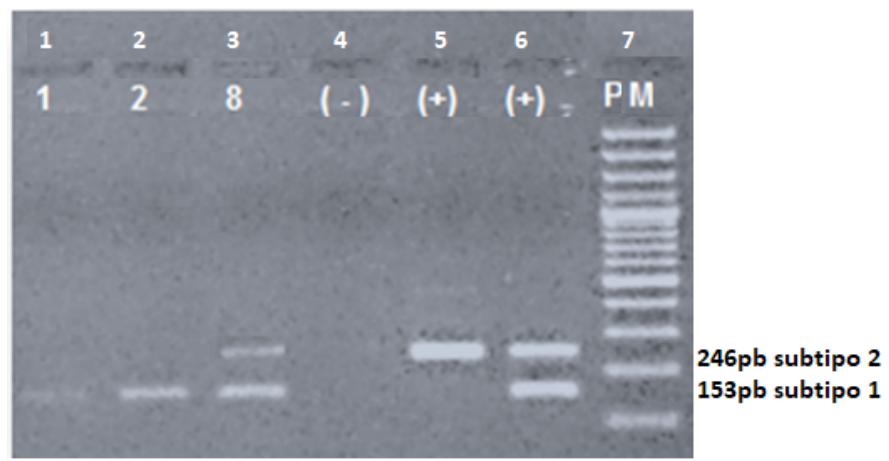

Figura 1. Tipificación del EBV mediante la amplificación del gen EBNA3C por PCR convencional. El subtipo 1 del EBV se caracteriza por presentar un tamaño de fragmento de $153 \mathrm{pb}$ y, el subtipo 2, uno de 246 pb. En los carriles 1 y 2 se observa el EBV del subtipo 1, muestras 1 y 2 ; en el carril 3, la exposición simultánea a los dos subtipos, muestra 8; en el carril 4, el control negativo; en los carriles 5 y 6 , los controles positivos del subtipo 2 y ambos subtipos, respectivamente; y en el carril 7, el peso molecular (PM). 
Cuadro 1. Relación de los aislamientos de adolescentes de Cali, Colombia, usados para identificar variantes con sus respectivas características

\begin{tabular}{|c|c|c|c|}
\hline ID de la muestra & $\begin{array}{l}\text { Cambios en los aminoácidos en la } \\
\text { región C-terminal de la proteína LMP1* }\end{array}$ & $\begin{array}{l}\text { Grupo de } \\
\text { Variante }\end{array}$ & $\begin{array}{l}\text { Característica } \\
\text { de la variante }\end{array}$ \\
\hline Cali EBV 1 & A210N, G212S, H213N & Raji & Patogénica \\
\hline Cali EBV 2 & G212S, H213N & Mediterráneo & No patogénica \\
\hline Cali EBV 3 & G212S, N218K, G230E & Cali & Indeterminada \\
\hline Cali EBV 4 & G212S, H213N & Raji & Patogénica \\
\hline Cali EBV 5 & D210AN, G212S, V228E & Mediterráneo & No patogénica \\
\hline Cali EBV 6 & G212S, N218K, L226H & Raji & Patogénica \\
\hline Cali EBV 7 & G212S, H213N, S229T & Mediterráneo & No patogénica \\
\hline Cali EBV 8 & G212S, S229T & Mediterráneo & No patogénico \\
\hline Cali EBV 9 & G212S, H213N, L226H & Raji & Patogénica \\
\hline Cali EBV 10 & N218K, L226H, V228E & Raji & Patogénica \\
\hline Cali EBV 11 & G212S, L226H & Raji & Patogénica \\
\hline Cali EBV 12 & D210N, G212S, L248Q & Cali & Indeterminada \\
\hline Cali EBV 13 & L226H, G230E & Raji & Patogénica \\
\hline Cali EBV 14 & G212S, H213N, L226H & Raji & Patogénica \\
\hline Cali EBV 15 & G12S, S229T, L248Q & Cali & Indeterminada \\
\hline Cali EBV 16 & D210NA, G212S, H213N & Raji & Patogénica \\
\hline Cali EBV 17 & A210D, H213N & Raji & Patogénica \\
\hline Cali EBV 18 & G212S, L226H & Raji & Patogénica \\
\hline Cali EBV 19 & G212S, H213N & Raji & Patogénica \\
\hline Cali EBV 20 & G212S, L226H & Raji & Patogénica \\
\hline Cali EBV 21 & G212S, H213N & Raji & Patogénica \\
\hline Cali EBV 22 & G212S, H213N & Raji & Patogénica \\
\hline Cali EBV 23 & G212S, H213N, N218K & Raji & Patogénica \\
\hline Cali EBV 24 & G212S, H213N & Raji & Patogénica \\
\hline Cali EBV 25 & Al10D, G212S, H213N, G212S, H213N & Raji & Patogénica \\
\hline Cali EBV 26 & A210D, G212S, H213N & Raji & Patogénica \\
\hline Cali EBV 27 & G212S, S229T & Cali & Indeterminada \\
\hline Cali EBV 28 & D210N, G212S, H213N & Raji & Patogénica \\
\hline Cali EBV 29 & G212S, H213N, & Raji & Patogénica \\
\hline
\end{tabular}

^El cambio de aminoácido fue determinado por comparación con la secuencia de referencia ID: NC_007605

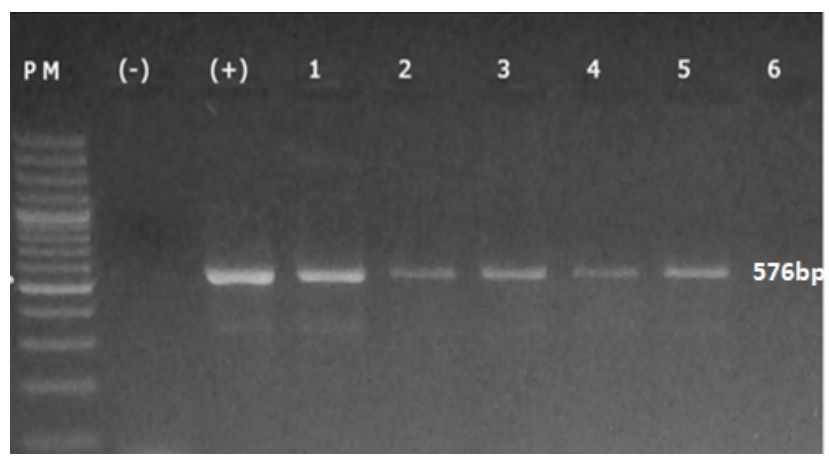

Figura 2. Amplificación por PCR convencional del fragmento C-terminal del gen BNLF1 del EBV. En la figura se observa la amplificación de un fragmento de 576 pb que codifica para el dominio C-terminal de la proteína viral LMP1. PM: peso molecular; (-) control negativo; (+) control positivo; muestras 1 a 6

Las 29 secuencias de los EBV detectados conformaron tres agrupaciones, una con los 21 aislamientos de Cali $(72,6 \%)$ relacionados con la línea celular Raji (KF717093.1, identidad del $99 \%$ ) con un remuestreo de $74 \%$; la otra agrupación presentó cuatro aislamientos de Cali (13,7\%) relacionados con el Mediterráneo (AY337722.2, identidad del $98 \%$ ) con un remuestreo de $83 \%$ y, por último, cuatro muestras de Cali $(13,7 \%)$, con un remuestreo de $81 \%$, que no se agruparon con ninguna de las líneas celulares ni con las regiones geográficas consideradas en el análisis, por lo que se decidió denominarla como variante Cali (EBV Cali). 


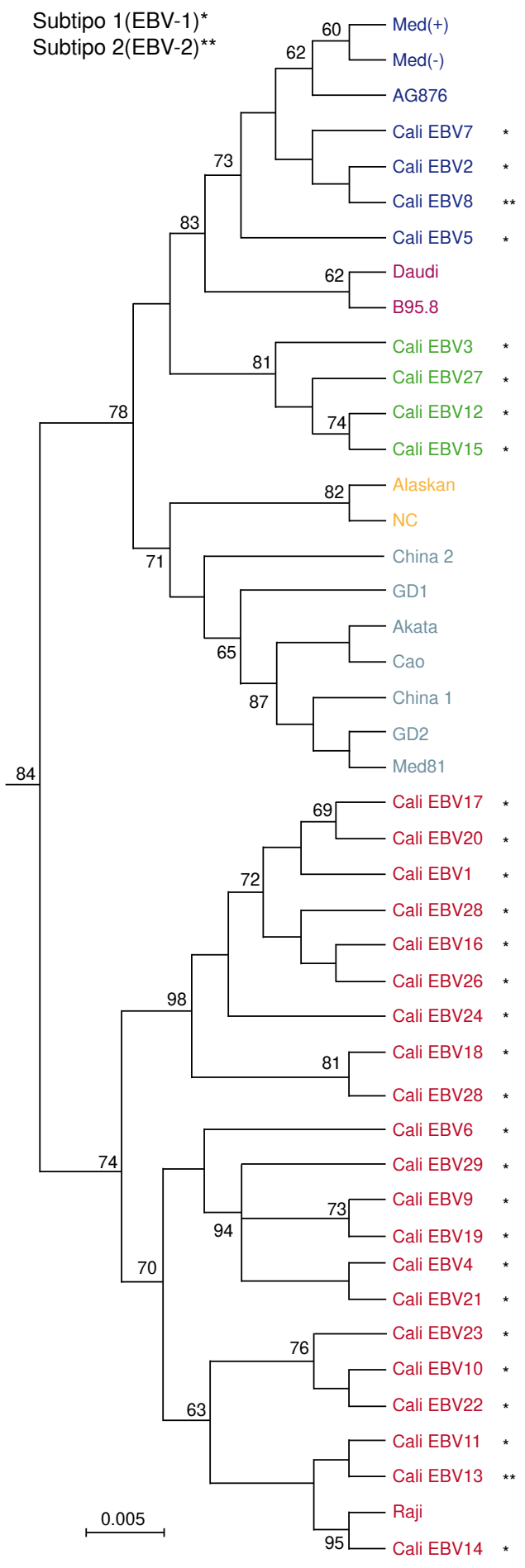

Figura 3. Filogenia de los EBV presentes en Cali, Colombia. Para la construcción del árbol filogenético se amplificó y secuenció un fragmento de $576 \mathrm{pb}$ de la región C-terminal del gen $B N L F 1$. En la figura se observan las agrupaciones filogenéticas obtenidas y valores de remuestreo mayores de $60 \%$ obtenidos al realizar 1.000 réplicas. La escala indica el número de sustituciones por sitio y a cada variante se le asignó un color: Mediterráneo, azul; Raji, rojo; Cali, verde; Alaska y Carolina del Norte, amarillo; Daudi y B95.8, violeta.

\section{Análisis de las variantes moleculares}

Al analizar las variantes encontradas en los aislamientos de Cali en relación con el genoma de referencia del EBV, se encontraron 20 mutaciones no sinónimas; la más frecuente fue la Gly212Ser, en $86,20 \%$ de los aislamientos, seguida de la His213Asn, con $58 \%$, y la Leu226His, con $27 \%$ (cuadro 1). 


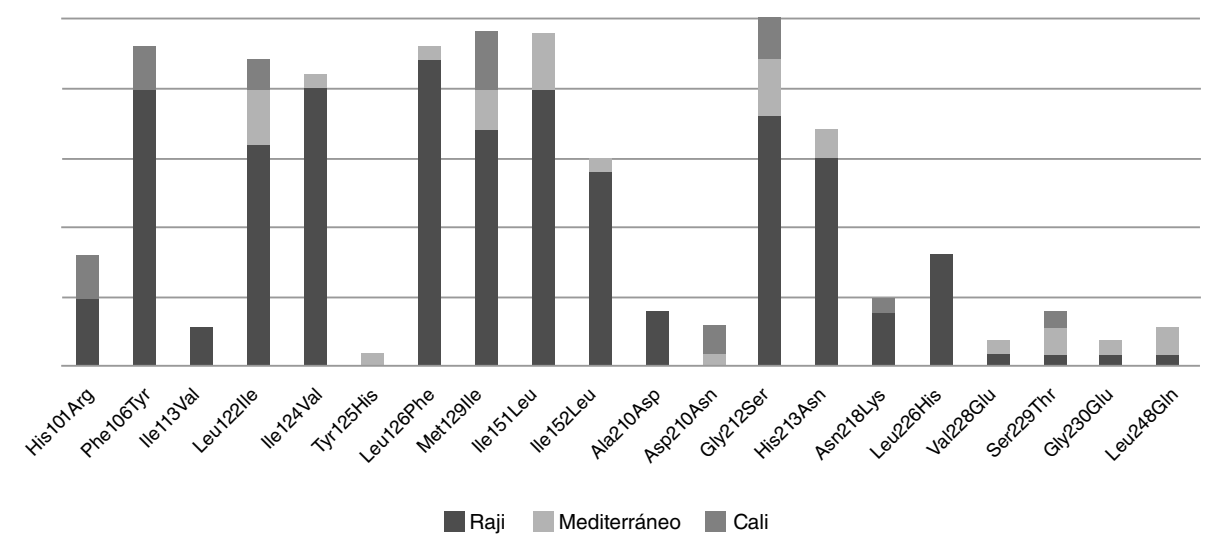

Figura 4. Distribución de las variantes moleculares identificadas en la región C-terminal de la proteína LMP1 de los EBV presentes en Cali. Se identificaron 20 mutaciones no sinónimas; la más frecuente fue el cambio de glicina por serina en la posición 212 (Gly212Ser), con un porcentaje del $86,2 \%$, seguido del cambio de metionina por leucina en la posición 129 e isoleucina por leucina en la posición 151, con un porcentaje de 79 \%. En las muestras agrupadas con la variante patogénica Raji, se encontró un mayor número de cambios de aminoácidos, seguidas de aquellas agrupadas con las variantes Mediterráneo y Cali; los cambios de aminoácidos de alanina por ácido aspártico en la posición 210 (Ala210Asp) y de leucina por histidina en la posición 226 (Leu226His), se identificaron exclusivamente en los aislamientos relacionados con la variante Raji, en tanto que el cambio de tirosina por histidina en la posición 125 (Tyr125His) se identificó exclusivamente en los relacionados con la Mediterráneo; el grupo exclusivo de Cali no presentó cambios de aminoácidos no reportados.

Los cambios encontrados se relacionaron según las variantes del EBV (figura 4) y se evidenció que aquellos asociados con Raji presentaron la mayor cantidad de mutaciones, seguidos de los asociados con la variante Mediterráneo y la agrupación de Cali. Además, se observó que las mutaciones Ala210Asp (13\%) y Leu226His (27\%) eran exclusivas de los aislamientos relacionados con Raji. No se encontró ningún cambio exclusivo para los aislamientos relacionados con el Mediterráneo o con la agrupación de Cali.

\section{Discusión}

En el presente estudio se reportan por primera vez los subtipos virales del EBV presentes en la cavidad oral de adolescentes de Cali, Colombia. El subtipo 1 se identificó en el $79 \%$ las muestras positivas para EBV, en tanto que el subtipo 2 se identificó en el $19 \%$. Además, se reportó una exposición simultánea de los subtipos del $2 \%$.

Un mayor porcentaje del subtipo 1 del EBV era lo esperado, ya que es el subtipo predominante a nivel mundial, en tanto que el 2 es más frecuente en la región subsahariana de África.

En cuanto al porcentaje de homología del gen EBNA3 del EBV, se ha reportado que el subtipo 1 difiere del subtipo 2 entre 10 y $20 \%$, y funcionalmente, el subtipo 1 ha demostrado gran capacidad para inmortalizar las células $B$ en la infección primaria, en comparación con el subtipo 2 (36). La diferencia genómica global entre estos dos subtipos no se ha establecido del todo, puesto que se han secuenciado pocos genomas completos de subtipo $2(28,37)$.

En los estudios de Chang, et al., que combinaron estudios poblacionales de subtipos en la población caucásica, se encontró que el $74 \%$ estaba infectado con el EBV del subtipo 1, $19 \%$ con el del subtipo 2 y el $7 \%$ con ambos 
subtipos (7). Asimismo, en los estudios realizados en Argentina por Chabay, et al., se estableció que el subtipo del EBV predominante era el 1 (38). Por su parte, Correa, et al., reportaron la presencia del subtipo 1 en $75,9 \%$ de pacientes argentinos adultos sanos seropositivos para el EBV, del subtipo 2 en el $17,6 \%$ y en $6,5 \%$ hubo infección simultánea con ambos subtipos (39).

En cuanto al bajo porcentaje de exposición simultánea en el presente trabajo, probablemente se debió a la poca edad de los participantes en el estudio. En los estudios realizados en China, Ai, et al., evaluaron 107 pacientes pediátricos con mononucleosis infecciosa y no se detectó la presencia simultánea de los dos subtipos de EBV en los niños, a pesar de haber padecido la enfermedad a temprana edad (40). En Argentina, Lorenzetti, et al., evaluaron 35 pacientes pediátricos con esta enfermedad y tampoco detectaron la presencia simultánea de los dos subtipos (16).

En los estudios recientes de análisis de los genomas completos del EBV, se ha establecido una gran variabilidad en las secuencias nucleotídicas del gen BNLF1 que codifica para la proteína LMP1; estas variantes incluyen polimorfismos de nucleótidos únicos (Single Nucleotide Polymorphisms, SNP), deleciones, inserciones y un número variable de repeticiones en tándem $(30,41)$. En este campo, los estudios se han enfocado en la presencia de variantes moleculares en la región C-ter de la proteína LMP1. Según Chang, et al., la presencia de estas variantes podría alterar la señalización intracelular mediada por la proteína viral LMP1, por lo cual el análisis de variantes en esta región podría explicar el potencial patológico de la proteína (7).

En el presente estudio, la reconstrucción filogenética de las variantes de la LMP1 evidenció que ninguno de los EBV detectados en Cali se agrupó con la variante patogénica prototipo B95.8, predominante en población europea $(42,43)$. Además, se observó que las variantes geográficas China 1, GD2, Cao y Akata se encuentran estrechamente relacionadas entre sí, al igual que las dos variantes geográficas del Mediterráneo, en tanto que las variantes geográficas China 2, NC y Alaskan conforman grupos independientes entre sí y con respecto a las otras variantes. Estos resultados concuerdan con los descritos por Edwards, et al. (26), y más recientemente, por Saechan, et al. (44).

En un estudio realizado en Argentina en una cohorte de pacientes con mononucleosis infecciosa y linfomas positivos para EBV, en la secuenciación de la región C-ter de la proteína viral LMP1, la variante geográfica China 1 fue la de mayor frecuencia (16). Cuando los investigadores obtuvieron la secuencia completa del gen BNLF1, el análisis filogenético evidenció que aquellas variantes previamente clasificadas como China1 tenían una relación más cercana con la variante patogénica de la línea celular Raji (45), primera línea celular humana de origen hematopoyético obtenida en 1963 de un paciente nigeriano de 11 años con linfoma de Burkitt (46). En el presente trabajo, no se encontraron variantes de China 1 en los EBV presentes en Cali, sin embargo, se identificaron variantes patogénicas en la línea celular Raji.

Además, en los EBV detectados en Cali se identificaron variantes presentes en los aislamientos del EBV de origen en el Mediterráneo. En los estudios de Mei-Liao, et al., se determinó una distribución global de las variantes del Mediterráneo, las cuales se identificaron en poblaciones de países con geografías muy diferentes como Ghana, Brasil, Estados Unidos, Kenia, Argentina y Australia. Las variantes del Mediterráneo también se han encontrado en los EBV presentes en pacientes aparentemente sanos sin que se hayan relacionado directamente con enfermedades $(43,47)$. 
Un hallazgo importante del presente estudio fue que $13,7 \%$ de los EBV en Cali presentaron variantes que no se identificaron ni agruparon con las variantes patogénicas de las líneas celulares o las variantes geográficas incluidas en el estudio. Se requerirán estudios adicionales para caracterizar dichas variantes y establecer si se relacionan con alguna enfermedad asociada con el EBV o si se trata de una variante geográfica propia de la ciudad de Cali.

Hasta el momento, los estudios de EBV en Colombia se han centrado en la relación del virus con el desarrollo de diferentes enfermedades. En Cali, Carrascal, et al., examinaron 178 casos de carcinoma gástrico y detectaron el EBV en el $13 \%$ de los pacientes, lo que sugiere una relación del virus con neoplasias malignas (48). Quijano, et al., detectaron el virus en el 56,7\% de personas con linfoma de Hodgkin (9). En pacientes pediátricos con trasplante hepático, Mesa, et al., encontraron una relación entre el control de replicación del EBV y el grado de inmunosupresión de los pacientes (49).

El grado de variabilidad del gen BNLF1 respalda la presencia de variantes moleculares observadas en los EBV aislados en Cali. Una posible explicación es que las proteínas de latencia del EBV, como la LMP1, podrían presentar una tasa de mutación en ciertas regiones de su estructura dependiente de la presión que ejerce el sistema inmunitario del huésped (30).

En un gran porcentaje $(86,6 \%)$ de las secuencias obtenidas de la región C-ter, se encontró el cambio de aminoácidos de glicina a serina en la posición 212 (Gly212Ser), cambio que se ha reportado con mucha frecuencia en varias partes del mundo $(50,51)$, con excepción de Rusia, donde hasta el momento no se ha observado esta mutación (52) y sí, en cambio, la sustitución de un ácido glutámico a glutamina en la posición 328 (Glu328GIn) en pacientes y personas sanas, el cual no se ha reportado en otras regiones del mundo $(53,54)$. En el presente análisis, no se encontró el cambio Glu328Gln, por lo que se validó la presencia de variantes del gen de la LMP1 únicas para ciertas regiones del mundo.

Una limitación del estudio fue el poco número de muestras del total disponible con EBV, pues se logró amplificar el producto de PCR de 576 pb de la región C-terminal de la LMP1 para la secuenciación en 29 de 84, debido probablemente a la fragmentación del ADN. Cabe anotar que, para la detección inicial del EBV, se amplificó un fragmento de $96 \mathrm{bp}$. Otra limitación fue el no encontrar estudios en que se hayan determinado subtipos y variantes del EBV en otras ciudades de Colombia, por lo que no fue posible hacer comparaciones.

En conclusión, en Cali está presente el subtipo 1 del EBV y las variantes Raji (patogénica) y Mediterráneo (geográfica); además, se detectó una variante que no se pudo agrupar con las variantes reportadas en la literatura especializada.

\section{Referencias}

1. Epstein MA, Achong BG, Barr YM. Virus particles in cultured lymphoblasts from Burkitt's lymphoma. Lancet. 1964;1:702-3. https://doi.org/10.1016/S0140-6736(64)91524-7

2. Rickinson A, Kieff E. Epstein Barr virus. In: Knipe DM, Howley PM, editors. Fields virology. $5^{\text {th }}$ edition. Philadelphia: Lippincott Williams \& Wilkins; 2007. p. 2655-700.

3. Higgins CD, Swerdlow AJ, Macsween KF, Harrison N, Williamns H, McAulay K, et al. A study of risk factors for acquisition of Epstein-Barr virus and its subtypes. $J$ Infect Dis. 2007; 195:474-82. https://doi.org/10.1086/510854

4. Pagano J. Is Epstein-Barr virus transmitted sexually? J Infect Dis. 2007;195:469-70. https://doi.org/10.1086/510861 
5. Grünewald K, Desai P, Winkler D, Heymann J, Belnap D, Baumeister W, et al. Threedimensional structure of herpes simplex virus from cryo-electron tomography. Science. 2003;302:1396-8. https://doi.org/10.1126/science.1090284

6. Sample J, Young L, Martin B, Chatman T, Kieff E, Rickinson A, et al. Epstein-Barr virus types 1 and 2 differ in their EBNA-3A, EBNA-3B, and EBNA-3C genes. J Virol. 1990;64:4084-92.

7. Chang CM, Yu KJ, Mbulaiteye SM, Hildesheim A, Bhatia K. The extent of genetic diversity of Epstein-Barr virus and its geographic and disease patterns: A need for reappraisal. Virus Res. 2009;143:209-21. https://doi.org/10.1016/j.virusres.2009.07.005

8. Chabay P, Preciado MV. Epidemiology of Epstein-Barr virus-associated pediatric lymphomas from Argentina. Bol Med Hosp Infant Mex. 2016;73:47-54. https://doi.org/10.1016/j.bmhimx.2015.12.002

9. Gallart-Catalá A. Infecciones por el virus de Epstein-Barr: mononucleosis infecciosa. 9a edición. Madrid: Editorial Tratado de Pediatría; 2006. p. 449-55.

10. Trastoy R, Costa J, Rodríguez J, Navarro D, Barbeito G, Aguilera A. Primoinfección por el virus Epstein-Barr entre los años 2006 a 2015 en el área sanitaria de Santiago de Compostela. Relación con edad y sexo. Rev Esp Quimioter. 2017;30:468-71.

11. Young L, Murray P. Epstein-Barr virus and oncogenesis: From latent genes to tumours. Oncogene. 2003;22:5108-21. https://doi.org/10.1038/sj.onc.1206556

12. Niedobitek G, Meru N, Delecluse H. Epstein-Barr virus infection and human malignancies. Int J Exp Pathol. 2001;82:149-70. https://doi.org/10.1111/j.1365-2613.2001.iep190.X

13. Chang Y, Moore PS, Weiss RA. Human oncogenic viruses: Nature and Discovery. Philos Trans R Soc Lond B Biol Sci. 2017;372:1732-8. https://doi.org/10.1098/rstb.2016.0264

14. Medina-Ortega A, López-Valencia D, Mosquera-Monje S, Mora-Obando D, Dueñas-Cuéllar A. Virus de Epstein-Barr y su relación con el desarrollo del cáncer. latreia. 2017;30:131-45. https://doi.org/10.17533/udea.iatreia.v30n2a03

15. Tsao SW, Tsang CM, Lo KW. Epstein-Barr virus infection and nasopharyngeal carcinoma. Philos Trans R Soc Lond B Biol Sci. 2017;19:372. https://doi.org/10.1098/rstb.2016.0270

16. Lorenzetti MA, Gantuz M, Altcheh J, De Matteo E, Chabay P, Preciado M. Distinctive EpsteinBarr virus variants associated with benign and malignant pediatric pathologies: LMP1 sequence characterization and linkage with other viral gene polymorphisms. J Clin Microbiol. 2012;50:609-18. https://doi.org/10.1128/JCM.05778-11

17. Gantuz M. Identificación y caracterización molecular y funcional de variantes de la proteína latente de membrana 1 del virus de Epstein Barr (tesis). Buenos Aires: Universidad de Buenos Aires; 2016. Fecha de consulta: 20 de septiembre de 2018. Disponible en: https:// bibliotecadigital.exactas.uba.ar/download/tesis/tesis n6055 Gantuz.pdf

18. Izumi K, Kaye K, Kieff E. The Epstein-Barr virus LMP1 amino acid sequence that engages tumor necrosis factor receptor associated factors is critical for primary B lymphocyte growth transformation. Proc Natl Acad Sci USA.1997;94:1447-52. https://doi.org/10.1073/pnas.94.4.1447

19. Young LS, Rickinson AB. Epstein-Barr virus: 40 years on. Nat Rev Cancer. 2004;4:757-68. https://doi.org/10.1038/nrc1452

20. Holthusen K, Talaty P, Everly DN Jr. Regulation of latent membrane protein 1 signaling through interaction with cytoskeletal. J Virol. 2015;89:7277-90. https://doi.org/10.1128/JVI.00321-15

21. Tsao SW, Tramoutanis G, Dawson CW, Lo AK, Huang DP. The significance of LMP1 expression in nasopharyngeal carcinoma. Semin Cancer Biol. 2002;12:473-87. https://doi.org/10.1016/s1044579x02000901

22. Dawson C, Port R, Young L. The role of the EBV-encoded latent membrane proteins LMP1 and LMP2 in the pathogenesis of nasopharyngeal carcinoma (NPC). Semin Cancer Biol. 2012;22:144-53. https://doi.org/10.1016/j.semcancer.2012.01.004

23. Kieser A, Sterz KR. The latent membrane protein 1 (LMP1). Curr Top Microbiol Immunol. 2015;391:119-49. https://doi.org/10.1007/978-3-319-22834-1 4

24. Vaysberg MO, Hatton SL, Lambert AL, Snow B, Wong SM, Krams S, et al. Tumor-derived variants of Epstein-Barr virus latent membrane protein 1 induce sustained Erk activation and c-Fos. J Biol Chem. 2008;283:36573-85. https://doi.org/10.1074/jbc.M802968200

25. Tzellos S, Farrell P. Epstein-Barr virus sequence variation - biology and disease. Pathogens. 2012;1:156-174. https://doi.org/10.3390/pathogens1020156 
26. Edwards $\mathrm{RH}$, Seillier-Moiseiwitsch F, Raab-Traub N. Signature amino acid changes in latent membrane protein 1 distinguish Epstein-Barr virus strains. Virology.1999;261:79-95. https://doi.org/10.1006/viro.1999.9855

27. Hatfull G, Bankier AT, Barrell BG, Farrell PJ. Sequence analysis of Raji Epstein-Barr virus DNA. Virology. 1988;164:334-40.

28. Dolan A, Addison C, Gatherer D, Davison AJ, McGeoch DJ. The genome of Epstein-Barr virus type 2 Strain AG876. Virology. 2006;350:164-70. https://doi.org/10.1016/. virol.2006.01.015

29. Lei H, Li T, Hung G, Li B, Tsai S, Lo S. Identification and characterization of EBV genomes in spontaneously immortalized human peripheral blood B lymphocytes by NGS technology. BMC Genomics. 2013;14:804. https://doi.org/10.1186/1471-2164-14-804

30. Santpere G, Darre F, Blanco S, Alcami A, Villoslada P, Mar AB, et al. Genome-wide analysis of wild-type Epstein-Barr virus genomes derived from healthy individuals of the 1,000 Genomes Project. Genome Biol Evol. 2014;6:846-60. https://doi.org/10.1093/gbe/evu054

31. Giraldo-Ocampo S, Osorio JC, Fernández A, Castillo A. Detección del virus Epstein Barr en escolares adolescentes en la ciudad de Cali, Colombia. Infectio. 2019;23:175-81. https://doi.org/10.22354/in.v23i2.775

32. Kingman DW, Weiss WB, Jaffe ES, Kumar S, Frekko K, Raffeld M. Epstein-Barr virus latent membrane protein-1 oncogene deletions: Correlations with malignancy in Epstein-Barr virusassociated lymphoproliferative disorders and malignant lymphomas. Blood.1996;88:242-51.

33. Zuo L, Yu H, Liu L, Tang Y, Wu H, Yang J, et al. The copy number of Epstein-Barr virus latent genome correlates with the oncogenicity by the activation level of LMP1 and NF-kB. Oncotarget. 2015;6:41033-44. https://doi.org/10.18632/oncotarget.5708

34. Kumar S, Stecher G, Tamura K. MEGA 7: Molecular Evolutionary Genetics Analysis version 7.0. Mol Biol Evol. 2016;33:1870-4. https://doi.org/10.1093/molbev/msw054

35. Thompson JD, Higgins DG, Gibson TJ. CLUSTAL W: Improving the sensitivity of progressive multiple sequence alignment through sequence weighting, position-specific gap penalties and weight matrix choice. Nucleic Acids Res.1994;22:4673-80.

https://doi.org/10.1093/nar/22.22.4673

36. Coleman C, Daud I, Ogolla S, Ritchie J, Smith N, Sumba P, et al. Epstein-Barr virus type 2 infects $t$ cells in healthy Kenyan children. J Infect Dis. 2017;216:670-7. https://doi.org/10.1093/infdis/jix363

37. Palser A, Grayson N, White R, Corton C, Correia S, Ba Abdullah M, et al Genome diversity of Epstein-Barr virus from multiple tumour types and normal infection. J Virol. 2015;89:5222-37. https://doi.org/10.1128/JVI.03614-14

38. Chabay P, De Matteo E, Merediz A, Preciado M. High frequency of Epstein Barr virus latent membrane protein-1 $30 \mathrm{bp}$ deletion in a series of pediatric malignancies in Argentina. Arch Virol. 2004;149:1515-26. https://doi.org/10.1007/s00705-004-0311-1

39. Correa R, Fellner M, Alonio L, Durand K, Teyssie A, Picconi M. Epstein-Barr virus (EBV) in healthy carriers: Distribution of genotypes and 30 bp deletion in latent membrane protein-1 (LMP-1) oncogene. J Med Virol. 2004;73:583-8. https://doi.org/10.1002/jmv.20129

40. Ai JH, Xie ZD, Liu CY, Gao LW, Yan J. Characteristic of nuclear antigen 1 gene and latent membrane protein 1 gene of Epstein-Barr virus in primary EBV infection in children in Beijin area in 2005-2010. Zhonghua Shi Yan He Lin Chuang Bing Du Xue Za Zhi. 2012;26:352-5.

41. Feederle R, Klinke O, Kutikhin A, Poirey R, Tsai MH, Delecluse HJ. Epstein-Barr virus: From the detection of sequence polymorphisms to the recognition of viral types. Curr Top Microbiol Immunol. 2015;390:119-48. https://doi.org/10.1007/978-3-319-22822-8 7

42. Chiara M, Manzari C, Lionetti C, Mechelli R, Anastasiadou E, Chiara M. et al. Geographic population structure in Epstein-Barr virus revealed by comparative genomics. Genome Biol Evol. 2016;8:3284-91. https://doi.org/10.1093/gbe/evw226

43. Smatti M, Yassine H, AbuOdeh R, AlMarawani A, Taleb S, Althani A, et al. Prevalence and molecular profiling of Epstein Barr virus (EBV) among healthy blood donors from different nationalities in Qatar. PLoS One. 2017;12:e0189033. https://doi.org/10.1371/journal.pone.0189033

44. Saechan V, Settheetham-Ishida W, Kimura R, Tiwawech D, Mitarnun W, Ishida T. EpsteinBarr virus strains defined by the latent membrane protein 1 sequence characterize Thai ethnic groups. J Gen Virol. 2010;9:2054-61. https://doi.org/10.1099/vir.0.021105-0 
45. Gantuz M, Lorenzetti MA, Chabay PA, Preciado M. A novel recombinant variant of latent membrane protein 1 from Epstein Barr virus in Argentina denotes phylogeographical association. PLoS One. 2017;10:1059-62. https://doi.org/10.1371/journal.pone.0174221

46. Karpova M, Schoumans J, Blennow E, Ernberg I, Henter J, Smirnov A, et al. Combined spectral karyotyping, comparative genomic hybridization, and in vitro apoptyping of a panel of Burkitt's lymphoma-derived B cell lines reveals an unexpected complexity of chromosomal aberrations and a recurrence of specific abnormalities in chemoresistant cell lines. Int $\mathrm{J}$ Oncol. 2006;26:605-17. https://doi.org/10.3892/ijo.28.3.605

47. Liao HM, Liu H, Lei H, Li B, Chin PJ, et al. Frequency of EBV LMP-1 promoter and coding variations in Burkitt lymphoma samples in Africa and South America and peripheral blood in Uganda. Cancers (Basel). 2018;10:177. https://doi.org/10.3390/cancers10060177

48. Carrascal E, Koriyama C, Akiba S, Tamayo O, Itoh T, Eizuru Y, et al. Epstein-Barr virusassociated gastric carcinoma in Cali, Colombia. Oncol Rep. 2003;10:1059-62. https://doi.org/10.3892/or.10.4.1059

49. Mesa J, Aristizábal B. Seguimiento con carga viral para virus Epstein-Barr en pacientes pediátricos con trasplante hepático. Médicas UIS. 2015;28:393-401. https://doi.org/10.18273/revmed.v28n3-2015015

50. Zuercher E, Butticaz C, Wyniger J, Martínez R, Battegay M, Boffi El, et al. Genetic diversity of EBV-encoded LMP1 in the Swiss HIV cohort study and implication for NF-Kb activation. PloS One. 2012;7:e32168. https://doi.org/10.1371/journal.pone.0032168

51. Nagamine $M$, Takahara $M$, Kishibe $K$, Nagat $T$, Ishii $H$, Bandoh $N$ et al. Sequence variations of Epstein-Barr virus LMP1 gene in nasal NK/Tcell lymphoma. Virus Genes. 2007;34:47-54. https://doi.org/10.1007/s11262-006-0008-5

52. Senyuta N, Yakovleva L, Goncharova E, Scherback L, Diduk S, Smirnova K, et al. EpsteinBarr virus latent membrane protein 1 polymorphism in nasopharyngeal carcinoma and other oral cavity tumors in Russia. J Med Virol. 2014;86:290-300. https://doi.org/10.1002/jmv.23729

53. Yakovleva L, Senyuta N, Goncharova E, Scherback L, Smirnova R, Pavlish O, et al. Epstein-Barr virus Imp1 oncogene variants in cell lines of different origin. Mol Biol (Mosk). 2015;49:714-22. https://doi.org/10.7868/S0026898415050213

54. Pavlish OA, Diduk SV, Smirnova KV, Shcherbak LN, Goncharova EV, Shalginskykh NA, et al Mutations of the Epstein-Barr virus LMP1 gene in Russian patients with lymphoid pathology and healthy individuals. Vopr Virusol. 2008;53:10-6. 